\title{
GIL MORLANES “EL VIEJO” Y MAESTRO HILARIO: UN RETABLO Y UNA REJA PARA LA CAPILLA DEL PALACIO DE LA DIPUTACIÓN DEL REINO DE ARAGÓN EN ZARAGOZA (1500-1514)
}

\author{
Santos M. Mateos Rusillo ${ }^{1}$ \\ Universitat de Vic-Universitat Central de Catalunya
}

El palacio de la Diputación del General del Reino de Aragón fue uno de los edificios más relevantes en la Zaragoza de los siglos XV y XVI. Provisto de una capilla privada para sus diputados y oficiales, su dotación artística a partir de 1500 se encargaría a relevantes artistas como el escultor Gil Morlanes «el Viejo», el rejero Maestro Hilario y los pintores Antón de Aniano y Pedro de Aponte, que la convertirían en uno de los espacios más esplendorosos de las artes figurativas de la Corona de Aragón de principios del siglo xvi. Se presenta la actuación de todos ellos en la obra de la reja y del retablo, aportándose nuevas noticias documentales sobre ambas obras; y la historia patrimonial del edificio hasta su desaparición en el siglo XIX.

Palabras clave: escultura; rejería; tardogótico; Gil Morlanes «el Viejo»; Maestro Hilario; Diputación del Reino de Aragón; Zaragoza.

\section{GIL MORLANES “THE ELDER" AND MASTER HILARIO: AN ALTARPIECE AND A GRILLE FOR THE CHAPEL IN THE PALACE OF THE DIPUTACIÓN OF THE KINGDOM OF ARAGON IN ZARAGOZA (1500-1514)}

The palace of the Diputación del General of the Kingdom of Aragon was one of the most important buildings in Zaragoza in the $15^{\text {th }}$ and $16^{\text {th }}$ centuries. Containing a private chapel for its deputies and officials, important artists such as the sculptor Gil Morlanes "the Elder", the iron-worker Master Hilario and the painters Antón de Aniano and Pedro de Aponte were commissioned to create its artistic endowment from 1500 onwards, something that would make it one of the most magnificent showcases of the figurative arts in the Crown of Aragon in the early $16^{\text {th }}$ century. The work of all of them is present in the making of the grille and the altarpiece. New documentary information is supplied about both works and the historical patrimony of the building until its disappearance in the $19^{\text {th }}$ century.

Key words: Sculpture, Iron-work, Late-Gothic, Gil Morlanes "the Elder", Master Hilario, Diputación of the Kingdom of Aragon, Zaragoza

Cómo citar este artículo / Citation: Mateos Rusillo, Santos M. (2021) "Gil Morlanes «el Viejo» y Maestro Hilario: un retablo y una reja para la capilla del palacio de la Diputación del Reino de Aragón en Zaragoza (1500-1514)”. En: Archivo Español de Arte, vol. 94, núm. 375, Madrid, pp. 215-232. https://doi.org/10.3989/aearte.2021.13.

\footnotetext{
${ }^{1}$ santos.mateos@uvic.cat / ORCID iD: https://orcid.org/0000-0003-2232-2126.
} 


\section{La construcción y dotación artística de la capilla²}

Vaclav Schaschek, un miembro de la comitiva del noble y diplomático bohemio León de Rosmithal de Blatna que le acompañó durante su viaje por España y Portugal en 1466, dejó una crónica escrita que relata su paso por Zaragoza para encontrarse con el rey Juan II. En ella ofrecerá una muy breve descripción en la que solo hará referencia a dos edificios, la capilla de la Virgen del Pilar y el palacio de la Diputación, del que dice: "Hay en Zaragoza una casa magnífica en que se suelen tener las Cortes". ${ }^{3}$ Levantado entre 1437 y 1450 en un lugar privilegiado de la ciudad, ${ }^{4}$ entre el palacio arzobispal y las casas de la Ciudad, junto a la iglesia de San Juan del Puente y la puerta del Ángel y muy cercano a la catedral de San Salvador y la iglesia de Santa María la Mayor y del Pilar [figs. 1, 2, 3 y 4], en el momento que la describe el viajero bohemio ya sobresalía por su magnificencia, aunque todavía faltaban unas cuantas décadas para que el edificio se enriqueciese aún más con la construcción y dotación artística de una capilla privada. ${ }^{5}$

La primera noticia documental sobre la edificación de una capilla en la planta baja del palacio data del año 1500. El 27 de mayo hay dos entradas en las cuentas de la Diputación que se refieren a las obras de la nueva sala. En una primera se pagaban 10.000 sueldos a mosén Pedro Sánchez y mosén Pedro Monterde, prior y tesorero de la catedral de San Salvador de Zaragoza y al caballero Carlos de Pomar, todos ellos diputados del Reino de Aragón, "por quanto de ordinación de los dipputados se ha fecho y faze una capilla dentro de las casas de la Dipputación, dentro la cambra de la
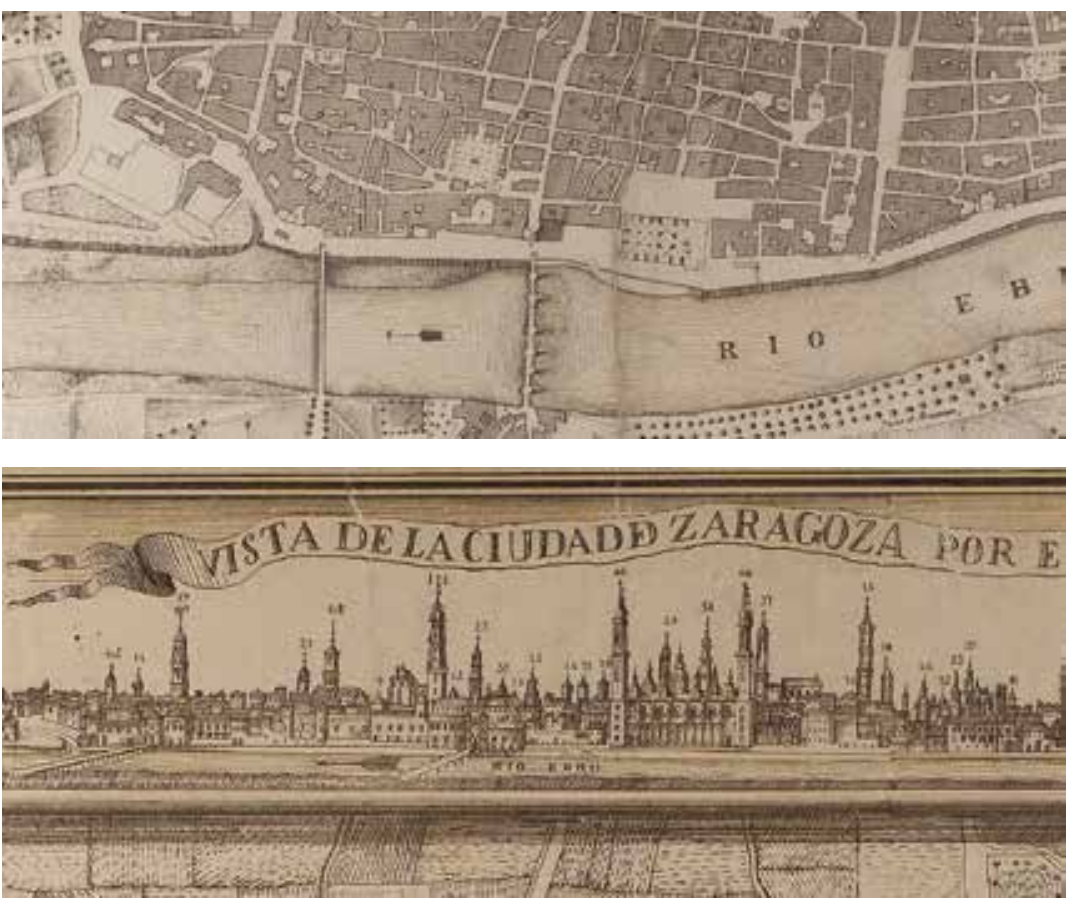

Fig. 1. Vista de la zona central de la fachada fluvial de Zaragoza. Plano levantado por Carlos Casanova (1766). El palacio de la Diputación es el marcado con el número 12 . Fuente: Archivo Municipal de Zaragoza.

Fig. 2. Vista del perfil de la zona central de la fachada fluvial de Zaragoza. Plano levantado por Carlos Casanova (1766). Fuente: Archivo Municipal de Zaragoza.

\footnotetext{
2 Agradezco a Maricruz Moreno, Álvaro Lafuente y Teresa Marruedo la amabilidad y facilidades para consultar los fondos documentales del Archivo de la Diputación Provincial de Zaragoza, algo especialmente de agradecer durante la difícil y trágica época que nos ha tocado vivir, la de la pandemia de la Covid-19.

3 Schaschek, 1879: 137-138.

4 Salord, 1956; Álvarez y Casabona, 1989; Gómez Urdáñez, 2011.

${ }^{5}$ La pista sobre la construcción y dotación artística de la capilla fue dada a conocer por José Ángel Sesma Muñoz en su tesis doctoral sobre la Diputación del Reino de Aragón defendida en 1977, publicada en Sesma, 1977: 164 y 241.
} 

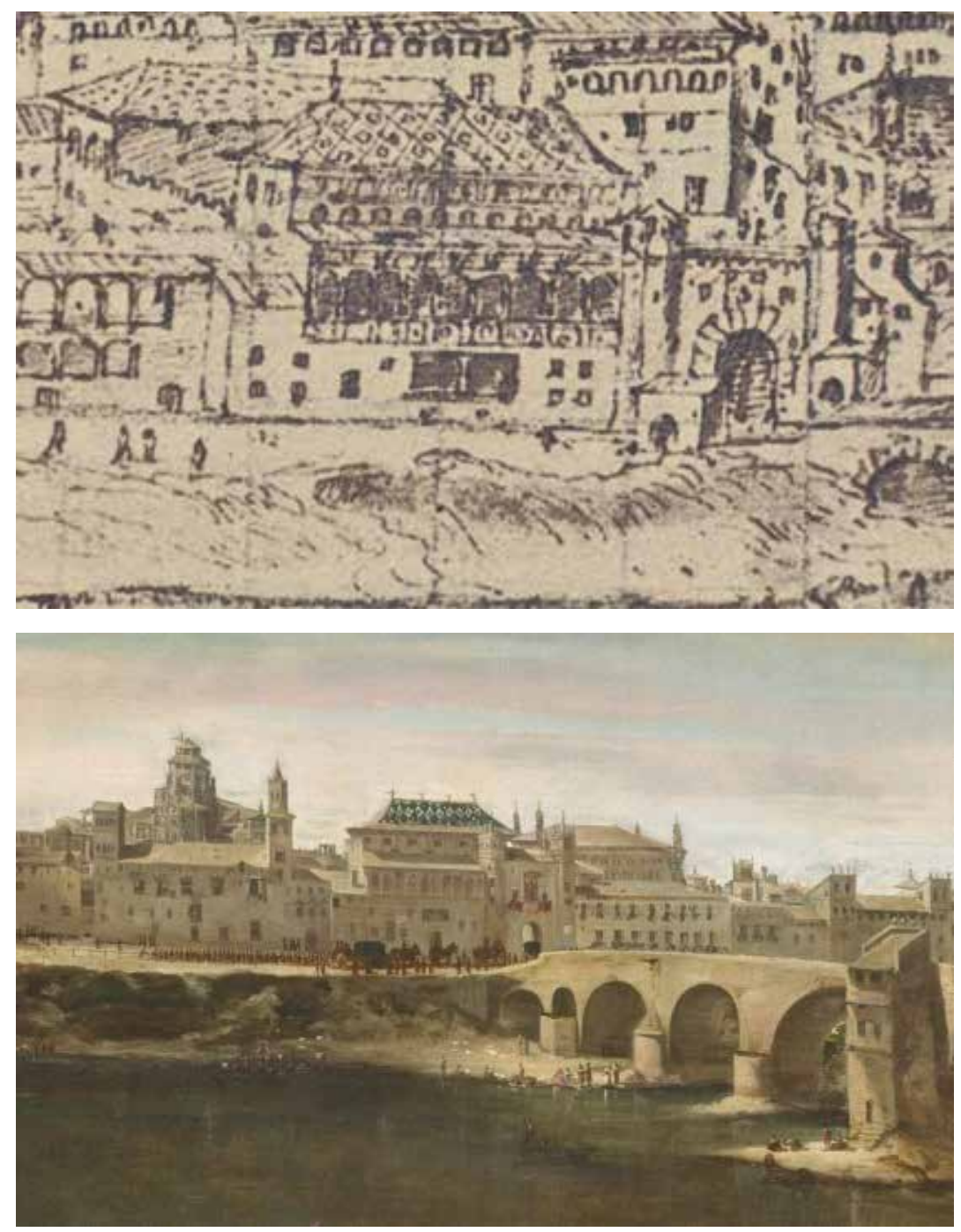

Fig. 3. Palacio de la Diputación con su mirador real o rico. Detalle de Vista panorámica de Zaragoza (1563) de Antoon van den Wijngaerde. Fuente: Wikimedia Commons.
Fig. 4. Palacio de la Diputación con su techumbre de tejas vidriadas bicromas. Detalle de Vista de Zaragoza (1647) de Juan Bautista Martínez del Mazo. Fuente: Museo Nacional del Prado.

sala jussana de aquellas", informándose del objetivo de su construcción "para donde huygan misa los dipputados y officiales de la dicha Dipputación e otros negociantes e ahún haviendo respetto que por los dipputados passados fue constituyda una misa perpetua en la yglesia de Sant Johan del Puent, mirando que tan insigne casa careçer de una tal joya en donde el culto divino se fiziesse y los dipputados y otros officiales y negocian[ $t$ ] es no quedassen sin hoyr misa". ${ }^{6}$ Por aquel entonces ya se habían comenzado las obras de construcción y se avanzaba que se tenía la intención de dotarla "de retablo y otras cosas neçessarias", cosa que ciertamente pasaría como se verá en este artículo. La segunda anotación son sendos pagos, uno a mosén Pedro Monterde por valor de 1.241 sueldos y 6 dineros, que los había adelantado de su propio peculio para principiar las obras, y otro a don Miguel Torrero, administrador, por valor de 8.118 sueldos y 6 dineros, "para que fiziesse y exsiguiesse la obra de la dicha capilla por él enpeçada".

${ }^{6}$ Zaragoza, ADPZ, Cuentas del General de Reino, 1500-1501, ms. 282, f. 168v. Aunque Antón de Sariñena era el maestro de obras de las casas de la Diputación desde el 24 de noviembre de 1477, cobrando por ello 100 sueldos anuales, siempre que se le paga algo nunca es referido a la obra de la capilla.

7 Ibidem supra. 
Meses después, el 30 de septiembre de 1500, los Diputados del General mandaban a don Juan Torrero, arrendador y administrador de las Generalidades del Reino, que pagase a los diputados Iván Coscón o Coscó y Juan de Lobera, nombrados "obreros e vehedores de la dicha obra" 200 florines de oro para proseguir con las obras de la capilla. ${ }^{8}$ El 8 de febrero de 1501 se les pagaban otros 200 florines de oro. ${ }^{9}$ Más de dos lustros después, el 28 de mayo de 1512, los diputados pasaban cuentas de los 400 florines pagados a Iván Coscón o Coscó y Juan Lobera por las obras de la capilla, informándose que se les había obligado a devolver 92 sueldos y 4 dineros. ${ }^{10}$

La obra tuvo que estar acabada necesariamente antes de 1502, ya que por entonces Gil Morlanes ${ }^{11}$ ya había asentado en ella su retablo de alabastro. Luego vendrían su policromado y dorado, junto al cortinaje para protegerlo de Antón de Aniano, las puertas pintadas por Pedro de Aponte, la reja de Maestro Hilario, su dorado y las pinturas murales y las tablas de altar pintadas por Antón de Aniano. Una capilla que se dotaría de otros elementos como claves y florones, obrados por Gil Morlanes y el fustero Antón Salas y pintados por el pintor maestro Miguel, respaldos de las sillas trabajados en madera de roble de Castilla por el maestro de obras Antón de Sariñena ${ }^{12}$ dos candelabros de plata para el altar del platero Andreu Martín, ${ }^{13}$ frontales de altar de damasco y terciopelo carmesí, ${ }^{14}$ etc.

Se conservan un conjunto de dos planos de sección o "perfil" y seis de planta, realizados en 1756 cuando el edificio era sede de la Real Audiencia de Zaragoza, dos de los cuales permiten situar el lugar exacto de la planta baja del palacio en el que se encontraba la capilla, ubicada en el bloque cuya fachada miraba al río Ebro y con ventanales que daban a la puerta del Ángel y las casas de la Ciudad, en el extremo noroeste de los planos [figs. 5 y 6 ] ${ }^{15}$ Como se comentará más adelante en el apartado que recorre la historia patrimonial de la capilla hasta su desaparición, en el momento que se levantaron estos planos la configuración arquitectónica y distribución de los muebles que la dotaban ya había sufrido cambios significativos acometidos en 1621, cuando se construye una bóveda de ladrillo con su decoración, se traslada de sitio el retablo y se crea tras él un espacio destinado a sacristía de la capilla y se coloca una cornisa de madera y mazonería sobre la reja. ${ }^{16}$

\section{El retablo de Gil Morlanes, ${ }^{17}$ Antón de Aniano y Pedro de Aponte (1500-1414)}

Gil Morlanes, natural de Daroca (Zaragoza) y formado en el oficio de escultor en la obra del retablo mayor de la Seo de San Salvador de Zaragoza como miembro del taller del maestro alemán

\footnotetext{
${ }^{8}$ Zaragoza, ADPZ, Registro de los Actos Comunes de la Diputación del Reino, 1500-1501, ms. 90, f. 21r (f. 16r antiguo).

${ }_{9}$ Zaragoza, ADPZ, Registro de los Actos Comunes de la Diputación del Reino, 1500-1501, ms. 90, f. 43r (f. 37r antiguo).

${ }^{10}$ Zaragoza, ADPZ, Registro de los Actos Comunes de la Diputación del Reino, 1511-1512, ms. 101, f. 130v (f. $106 \mathrm{v}$ antiguo).

${ }^{11}$ En este artículo se habla de Gil Morlanes padre, por lo que a partir de ahora se prescindirá del apelativo «el Viejo» que se utiliza para diferenciarlo de su hijo del mismo nombre y oficio, Gil Morlanes «el Joven».

12 Zaragoza, ADPZ, Registro de los Actos Comunes de la Diputación del Reino, 1503-1504, ms. 94, f. 26r/r (f. 21r/v antiguo) y $71 \mathrm{r}$ (f. 66r).

${ }_{13}$ Zaragoza, ADPZ, Registro de los Actos Comunes de la Diputación del Reino, 1503-1504, ms. 94, f. 93v (f. 88v antiguo).

${ }_{14}$ Zaragoza, ADPZ, Registro de los Actos Comunes de la Diputación del Reino, 1503-1504, ms. 94, f. 99r/v (f. 94r/v antiguo) y $100 \mathrm{v}$ (f. $95 \mathrm{v})$.

${ }_{15}$ Madrid, Archivo General Militar, Cartografía, Planos de la casa de Audiencias de Zaragoza. Año 1756, Z-03-07 y Z-03-08. La existencia de los planos fue dada a conocer por Giménez y Tomás, 2006: 15-19. Importante no confundir la capilla de la que aquí hablamos con la iglesia parroquial de San Juan del Puente, en el extremo opuesto e integrada en los planos del edificio.

${ }^{16}$ Toda la zona oeste del plano de planta levantado el 1 de marzo de 1756 en tinta negra (Z-03-08) es un añadido de papel superpuesto al plano original, que incluso impide ver la clave alfabética que identifica los espacios situados en ella. Se ha marcado en negro sobre el plano en color (Z-03-07) el espacio que ocuparía la capilla en el siglo XvI.

17 A la vista de la rica documentación conservada que cita al escultor, de todas las formas de nombrar su apellido la más utilizada es Morlán, siendo Morlanes la menos presente. No obstante, por ahora se sigue utilizando la forma usual de nombrarlo en la historiografía.
} 


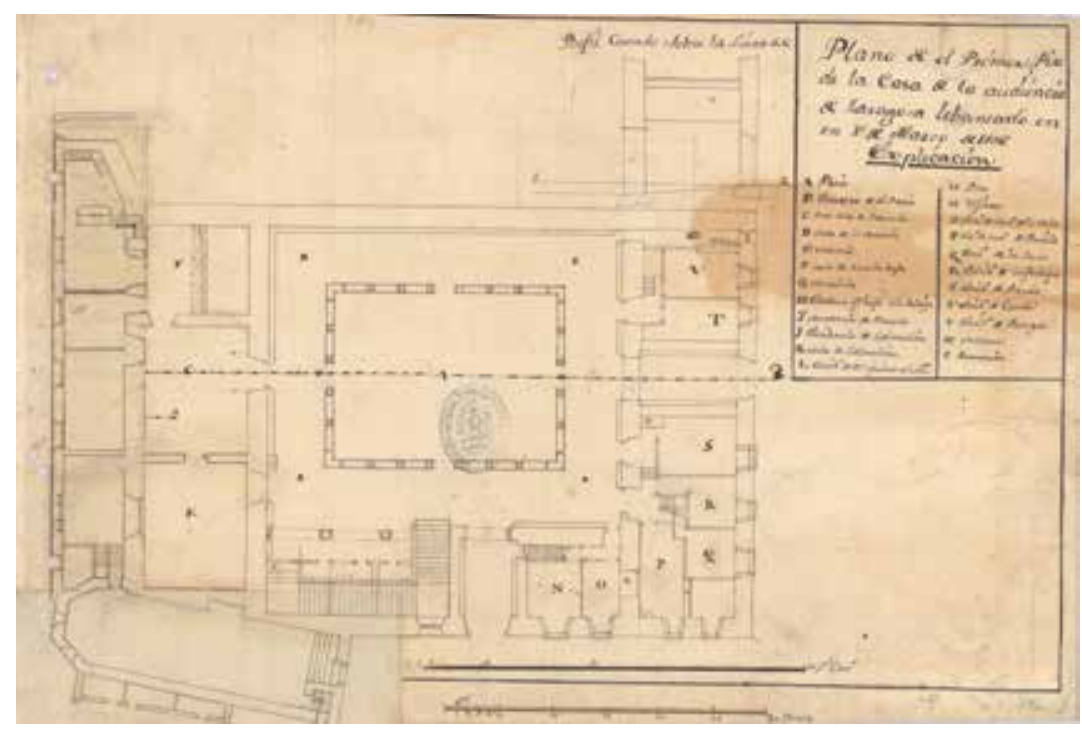

Fig. 5. Plano de la planta baja del palacio de la Diputación (1756). Fuente: Archivo General Militar de Madrid.

Hans Piet Danso, dominó en el tránsito del siglo Xv al XVI el panorama escultórico de la capital del Reino de Aragón. ${ }^{18}$ A lo largo de sus más de cuarenta años de trabajo (está documentado entre 1474 y 1515) acumuló importantes encargos de las élites de la corona aragonesa, organizando su taller de forma peculiar para responder a ellos y convirtiéndose en referente de la figura del artistaempresario. ${ }^{19}$ Una trayectoria vital y artística casi paralela al gobierno de la sede cesaraugustana del arzobispo Alonso de Aragón (1478-1520) y al reinado de Fernando II «el Católico» (14791516), ambos personajes relacionados directamente con el escultor, al que nombraron escultor a su servicio en 1484 y 1493, respectivamente..$^{20}$

La obra aquí tratada sería la primera que haría tras su vuelta a su casa y taller en la parroquia de San Juan del Puente de Zaragoza, después de su estancia en el monasterio de Santa María de Poblet (Tarragona) para la realización, por encargo de Fernando II, de los sepulcros de sus padres Juan II y Juana Enríquez para el Panteón Real del monasterio cisterciense. Una obra capital de su trayectoria artística que, como el retablo de la Diputación, también tuvo una trágica vida patrimonial durante el siglo XIX.

Luego vendrían otros importantes encargos como el retablo mayor de la iglesia del castilloabadía de Montearagón en Huesca (contratado en 1506), el sepulcro de don Juan de Lanuza y de Garabito y doña Beatriz de Lanuza y de Pimentel para la capilla de la familia en el claustro de la iglesia de Santa María la Mayor y del Pilar de Zaragoza (1508) y finalmente la que sería su última obra antes de fallecer y legar su taller a su hijo, Gil Morlanes «el Joven», la portada de la iglesia del Real Monasterio de Santa Engracia de Zaragoza (1514-1515).

La primera noticia que se tiene sobre la máquina data de 1901, cuando Tomás Ximénez de Embún, archivero municipal de Zaragoza, publicaba que el escultor "había labrado en 1502 un notable retablo de alabastro dividido en tres compartimentos; en el centro la coronación de la Virgen y en los costados, historias de San Jorge y Santa Engracia; costó la obra 1.200 ducados de oro". ${ }^{21}$ Una información muy precisa como para ser una fabulación de Ximénez de Embún, que además precisaba que la información constaba "por documentos auténticos". ${ }^{2}$

18 Serrano, 1916: 351-380, 1918a: 92-102 y 1918b: 357-359; Janke, 1988: 61-80.

19 Yarza, 1993: 367 y 1994: 153-154; Mateos, 2001: 551-557.

${ }^{20}$ El nombramiento por el arzobispo fue dado a conocer por Morte, 1998: 183 y publicado por Ibáñez, 2000: 305. El nombramiento por el monarca en Morte, 1981: 219 y 221.

21 Ximénez de Embún y Val, 1901: 31.

22 Ximénez de Embún y Val, 1901: 189. Nadie hasta ahora había dado a conocer esos documentos que vio y manejó Ximénez de Embún. 




Fig. 6. Plano de la planta baja del palacio de la Diputación (1756). Fuente: Archivo General Militar de Madrid.

No será hasta quince años más tarde que se publique la única referencia documental de la obra que se tenía hasta ahora. El 28 de mayo de 1916, Manuel Serrano y Sanz la dio a conocer en el marco de su ingreso en la Real Academia de Bellas Artes de San Luis de Zaragoza, concretamente en su disertación para el discurso de recepción académica, que al publicarse se convertirá en la obra de referencia para todo aquel que se aproxime a la figura del escultor darocense. Fechada el 12 de mayo de 1503, se trataba de un orden de pago que los Diputados del Reino de Aragón mandaban a los administradores don Juan Torrero y don Pedro Sánchez, a los que se pedía se pagasen al escultor 70 ducados por el "altar de barbastro, con ymagines e bosladina alderedor, con las armas del Regno, que las tienen dos ángeles, et a los costados, labrados de fullas a la romana, con su cobertor de alabastro" que por aquel entonces ya había realizado y asentado en su lugar de destino, la capilla de las Casas de la Diputación del General de Zaragoza. ${ }^{23}$

El documento exhumado por el bibliotecario caracense se trataba de las demasías pagadas al escultor una vez instalado y peritado el retablo "segunt la relación que teníamos de algunas personas dignas de fe que en ello entienden lo huviesse tachado en más precio. E sea cosa justa et razonable sea satisfecho et pagado de lo que por nosotros ha seÿdo concordado en dichos setenta ducados".

Ahora podemos corroborar documentalmente la información que avanzaba Ximénez de Embún en 1901, al exhumar cinco documentos más relacionados con la obra, en concreto tres cartas de pago fechadas en 1500,1501 y 1502 y dos anotaciones de pagos de 1502 y 1503 , procedentes de los Libros de Actas y Libros de Cuentas de la Diputación del Reino de Aragón. ${ }^{24}$

${ }^{23}$ Zaragoza, ADPZ, Registro de los Actos Comunes de la Diputación del Reino, 1502-1503, ms. 92, ff. 60v-61r (ff. 56v-57r antiguo). Documento publicado parcialmente por Serrano, 1916: 375.

${ }^{24}$ Aunque de los años aquí tratados se conservan la mayoría de los libros, hay lagunas que desgraciadamente coinciden con aspectos fundamentales de la construcción y dotación artística de capilla. Por ejemplo, y para los intereses de este artículo, faltan los manuscritos en los que se registraron las capitulaciones del retablo con Gil Morlanes y de la reja con Maestro Hilario. 
En el primer documento, una carta de pago fechada el 4 de noviembre de 1500, los Diputados del Reino de Aragón mandan al arrendador y administrador don Miguel Torrero que le pague 200 ducados de oro a Morlanes por "fazer el retablo de la dicha capilla de alabastro", una cantidad que Torrero recuperará cuando rinda cuentas de su administración. Como curiosidad, en esta anotación se refieren a él como "maestre Gil Ans". ${ }^{25}$

Una segunda ápoca del 31 de marzo de 1501 consigna un nuevo pago de otros 200 ducados. Más allá de los formulismos que se repiten en este tipo de cartas de pago, esta es interesante porque se califica el retablo como una obra "de muy grant costa". ${ }^{26}$

La siguiente referencia documental que se ha encontrado es la más interesante de todas ellas. Se trata de la carta de fin de pago ejecutada el 18 de julio de 1502. Aquel día, los Diputados del Reino de Aragón mandaban a los administradores don Juan Torrero y don Pedro de Juan Sánchez que se le pagasen 200 ducados de oro como parte de los 1.200 en que se capituló la obra, "hun retablo delabastro con las istorias de la coronación de Nuestra Sennora y sant Jorge e santa Engracia a los costados". En aquel momento el retablo ya estaba "atemado, asentado y puesto en perfección como havía de estar" y ya había cobrado los restantes 1.000 ducados, "ya reçebidos en partidas y por cautelas de los dichos Dipputados". ${ }^{27}$

En esta carta de pago se hace referencia a la capitulación de la obra, que por los pagos realizados se debió convenir entre los diputados y el escultor entre finales de 1499 y principios de 1500. Por desgracia no se conserva el manuscrito que contendría la capitulación y el resto de las cartas de pago de los 600 ducados de oro que faltan por documentar pero que serían cobrados por Morlanes.

Por último, en las cuentas del General del Reino de los años 1502-1503 hay una entrada fechada el 8 de abril de 1503 que recopila lo pagado hasta ese momento por Guiralt Sánchez, recaudador de la Diputación, a los artistas que participaban en la dotación artística de la capilla, un total de 1.398 libras, 12 sueldos y ocho dineros. ${ }^{28}$ Este documento se refiere como es natural al retablo, pero introduce una información de lo más interesante al reflejar que se pagaba "a maestre Gil de Molrans, a maestre Miguel, pintor, por el obrar de los claves y florones", que más adelante se vuelven a citar para asociarlos también "a maestre Anthón Salas, fustero, por fazer las claves y florones" [fig. 7]. ${ }^{29}$

En total, Gil Morlanes cobraría por el retablo de alabastro 1.270 ducados de oro (los 1.200 pactados por contrato más 70 ducados de demasías - que equivalían aproximadamente a unos 27.940 sueldos-). Una cifra muy pareja, aunque bastante superior a la que se embolsaría años después por el retablo mayor de la iglesia del castillo-abadía de Montearagón en Huesca, que ascendió a 23.000 sueldos [fig. 8]. Incluso cobró mucho más por el retablo que nos ocupa si se tiene presente que el dorado y policromado del retablo de Montearagón también iba incluido en el precio capitulado, mientras que aquí fue responsabilidad del pintor Antón de Aniano, que cobró por ello. La comparación entre ambas máquinas sirve para hacerse una idea bastante cabal de la magnitud que debió tener el retablo que Morlanes hizo para la Diputación.

Si se unen las sucintas descripciones que se ofrecen del retablo en los documentos de 1502 y 1503 se puede reconstruir mínimamente: tendría un cuerpo principal con una estructura central

${ }^{25}$ Zaragoza, ADPZ, Registro de los Actos Comunes de la Diputación del Reino, 1500-1501, ms. 90, f. 28r/v (f. 23r/v antiguo).

${ }^{26}$ Zaragoza, ADPZ, Registro de los Actos Comunes de la Diputación del Reino, 1500-1501, ms. 90, f. 51r/v (f. 45r/v antiguo).

${ }_{27}$ Zaragoza, ADPZ, Registro de los Actos Comunes de la Diputación del Reino, 1502-1503, ms. 92, ff. 22v-23r (ff. $18 \mathrm{v}-19 \mathrm{r}$ antiguo). Documento inédito publicado en el Apéndice documental, Documento 1. De esta última tanda hay anotación de un día después en el correspondiente libro de cuentas: Zaragoza, ADPZ, Cuentas del General de Reino, 1502-1503, ms. 89, f. 168 r.

${ }^{28} \mathrm{La}$ cantidad total incluye otros pagos por temas que nada tienen que ver con la capilla, por lo que no es posible conocer lo atribuido en exclusiva al recinto.

29 Zaragoza, ADPZ, Cuentas del General de Reino, 1502-1503, ms. 89, f. 174r. No se puede saber quién era el pintor que policromó las claves y florones, ya que por aquellos años estaban activos en Zaragoza varios pintores que podrían ser el "mastre Miguel" que se cita: Miguel Vallés, Miguel Ximénez o Miguel Martínez. 


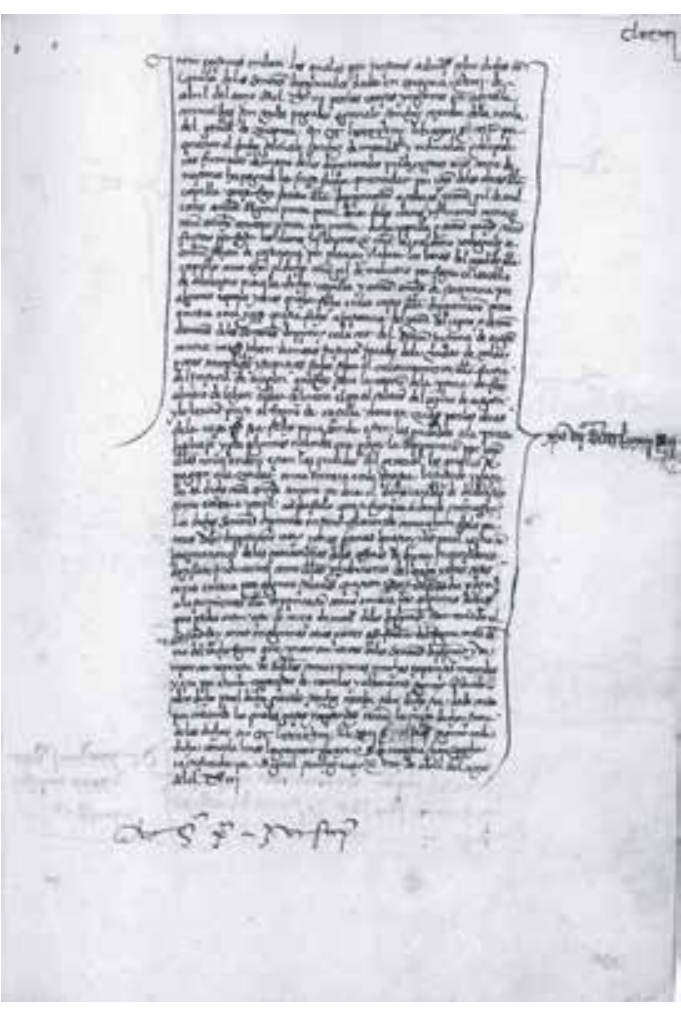

Fig. 7. Folio $174 \mathrm{r}$ del Ms. 89 con la recopilación de cuentas de 1502-1503 relacionadas con la dotación artística de la capilla. Fuente: ADPZ.

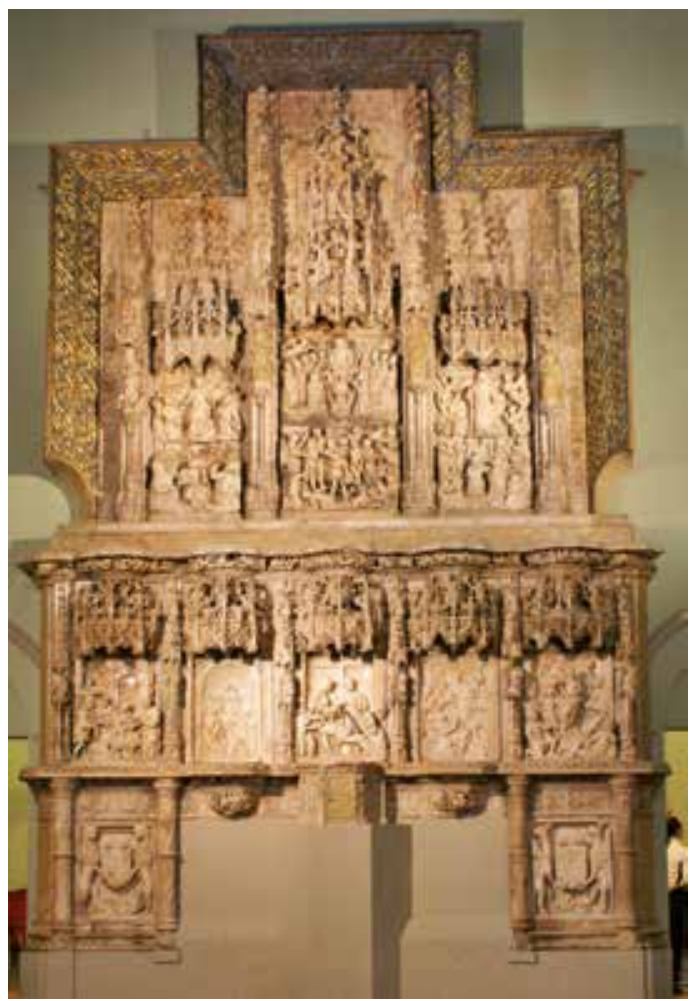

Fig. 8. Retablo mayor de la iglesia del castillo-abadía de Montearagón. Fuente: Museo Diocesano de Huesca.

dedicada a la Coronación de la Virgen y dos laterales ocupadas por historias de San Jorge y Santa Engracia; todo ello protegido por un guardapolvo con las armas del Reino de Aragón sostenidas por un par de ángeles y "los costados labrados de fullas a la romana, con su cobertor de alabastro", una temprana referencia a la entrada en Aragón de la influencia renacentista que permite considerar esta obra como pionera en esa introducción.

Por otra parte, también se conocía la documentación relacionada con el pintor que lo policromó y doró, Antón de Aniano, y el que hizo sus puertas, Pedro de Aponte, exhumada por Carmen Morte García en una monumental colección de artículos sobre pintura del siglo XVI en Aragón que había formado parte del apéndice documental de su tesis doctoral.

La obra realizada en alabastro por Morlanes sería policromada y dorada por "maestre Anthon Anyano pintor del retaulo de la capilla de la Dipputación", que entre el 6 de abril de 1503 y el 26 de abril de 1504 cobraba ciertas cantidades de los diputados por pintar "la capilla de la Dipputación altar retablo y rexado de aquella", trabajo convenido en 450 ducados de oro. ${ }^{30}$

En alguno de los documentos que vinculan a Antón de Aniano con el retablo, en concreto en dos cartas de pago del 6 de abril y del 15 de julio de 1503, se habla que se le había pagado ya por manos de Guiralt Sánchez 2.000 sueldos "por principiar de labrar el retablo de alabastro" y que le habían "dado a estallo (...) el dorar y labrar el retablo de alabastro". Teniendo presente que Aniano era pintor (en la primera ápoca se habla que había ya pintado la capilla por la que había cobrado 1.800 sueldos) y que en el resto de los documentos que le relacionan con el retablo está claro que

${ }^{30}$ Zaragoza, ADPZ, Registro de los Actos Comunes de la Diputación del Reino, 1502-1503, ms. 92, f. 52v (f. 48v antiguo) y f. 53r (f. 49r antiguo); Registro de los Actos Comunes de la Diputación del Reino, 1503-1504, ms. 94, ff. 21v$22 \mathrm{r}$ (ff. $16 \mathrm{v}-17 \mathrm{r}$ antiguos), f. $51 \mathrm{r}$ (46r antiguo), f. 65v (f. 60v antiguo), ff. $70 \mathrm{v}-71 \mathrm{r}$ (ff. 65v-66r antiguos) y f. 94v (f. 89v antiguo). Albares de pago dados a conocer y publicados por Morte, 1987a: 136-138. 
era el "pintor del retablo" o "pintor dorador del retablo" se debe interpretar como un error del escribano.

En una cautela relacionada con la reja, de la que se hablará más adelante, hay una valiosa información sobre la configuración final del retablo. El 9 de mayo de 1503 se ordenaba pagar a Antón de Aniano por un material que previamente había comprado el pintor a petición de los diputados, una "tela, veta negra, vara y sortijas de fierro (...) para la cortina que havemos mandado fazer para cobijar el retablo de la dicha capilla y por el coser de aquella y otros gastos menudos". ${ }^{31}$

El retablo, protegido por el cortinaje confeccionado por Aniano, volvería a cambiar de aspecto en 1514, cuando se instalarán unas puertas pintadas por el pintor Pedro de Aponte. Capituladas el 10 de febrero de 1508, Aponte las debía entregar e instalar el 1 de agosto de aquel mismo año. ${ }^{32}$ Algo importante debió ocurrir para impedir que el pintor cumpliera su compromiso, pues no estarían a punto para ser instaladas hasta seis años después. El impedimento tendría relación con el compromiso en otras obras, sumado a temas personales que harían que aquellos años fueran realmente trepidantes para él. Sabemos que en 1508 estaba pintando junto a Antón de Aniano un retablo para Borja (Zaragoza), un año después contrataba un retablo para la iglesia parroquial de Azanuy (Huesca), en 1511 se asociaba con el ya citado Aniano para afrontar con más garantías la inminente salida al mercado pictórico de varios retablos y entre 1511 y 1513 realizaba el retablo de la iglesia parroquial de Grañén (Huesca). En el terreno personal, se conoce que el 7 y el 9 de noviembre de 1510 dictaba testamento su mujer Catalina Camañas o de Rubert y se realizaba un inventario de sus bienes en la casa conyugal, sita en la parroquia de Santa Cruz, quedando viudo y con dos hijas menores a su cargo, Isabel y Jerónima. Años más tarde, en 1512 adquiría el compromiso de contraer matrimonio en segundas nupcias con la doncella María de Arruego, pero no firmaría las capitulaciones matrimoniales hasta $1520 .{ }^{33}$

En algún momento entre 1508 y 1514 las acabaría pintando, pues finalmente el 14 de junio de este último año eran reconocidas satisfactoriamente por el escultor Damián Forment y los pintores Jaime Romeo y Miguel Gil de Palomar. El 20 de junio se extendía la carta de fin de pago al pintor, cobrando un total de 7.997 sueldos por la obra y finalmente el 26 de junio se comprometía a reparar las puertas si era necesario, un compromiso que se extendía por espacio de diez años. ${ }^{34}$

Las puertas, un total de cuatro, tenían un alma "de fusta bien delgadas y guarnecidas", sobre las que asentaba "su tela bien delgada y bien pegada". Se le pedía a Aponte que fueran pintadas "de muy finas colores", explicitando el uso de azur de acre, carmesí y oro molido. Las historias que se tenían que pintar eran: en la cara externa los cuatro Doctores de la Iglesia (puertas superiores) y el Apostolado (puertas inferiores); y en la cara interna, dos historias de Santa Engracia y dos de San Jorge (puertas superiores) y cuatro historias de la Pasión de Cristo (puertas inferiores): la Oración en el huerto, la Flagelación, la Coronación de espinas y el Camino del Calvario.

La cantidad cobrada por Morlanes, junto a la descripción de las puertas de Aponte permiten hacerse una idea de cómo debió ser el retablo, sin duda una máquina imponente para la que incluso se nombró al pintor Antón de Aniano como conservador "por ser muy rico y sumptuoso". ${ }^{35}$

\section{La reja de Maestro Hilario y Antón de Aniano (1503-1504)}

La figura artística de Maestro Hilario, citado también como Hilario Francés, ha sido uno de los objetos de investigación del referente científico en el estudio de la rejería hispánica, Amelia

\footnotetext{
${ }^{31}$ Los diputados le pagaban por ello 198 sueldos el 8 de mayo de 1503 (la cantidad también incluía "el oro que ha entrado en el dorar las foxas de las faxas del dicho rexado"). Zaragoza, ADPZ, Registro de los Actos Comunes de la Diputación del Reino, 1502-1503, ms. 92, f. 55v (f. 51v antiguo).

${ }^{32}$ Zaragoza, ADPZ, Registro de los Actos Comunes de la Diputación del Reino, 1507-1508, ms. 98, f. 55r/v (f. 57r/v antiguo). Documento de capitulación y primer alabarán de pago dado a conocer y publicado por Morte, 1987a: 146-148.

${ }^{33}$ Abizanda, 1915: 25-26; Morte, 1987a: 149-153 y Velasco, 2020: 11 y 19.

${ }^{34}$ Zaragoza, ADPZ, Registro de los Actos Comunes de la Diputación del Reino, 1514, ms. 109, f. 12 y f. 161 (f. 7 y f. 150 antiguo). Carta de fin de pago, visura y compromiso dados a conocer y publicados por Morte, 1987a: 163-164.

35 Sesma, 1977: 165.
} 
Gallego de Miguel, que en sus trabajos lo documentará por tierras castellanas entre 1510-1526. La primera actividad documentada hasta ahora del rejero y relojero francés se situaba en Salamanca, donde se le documenta trabajando para la catedral charra en la reparación de su reloj y citado por el rector de la Universidad conminando al claustro a aprovechar su estancia en la ciudad para encargarle una reja para la capilla universitaria (en 1510 y en 1512). Más tarde se trasladaría hasta Burgos para realizar una reja para la catedral burgalesa por encargo del obispo don Pedro de Fonseca (no conservada) y su obra más relevante entre las documentadas, el barandal de la Escalera Dorada de la catedral de Burgos según una traza diseñada por Diego de Siloé (la obra de Hilario se documenta entre 1523-1526).$^{36}$ En 1528, citado como vecino de Burgos, se presenta al concurso para hacerse con la reja de la capilla mayor de la catedral de Coria, que finalmente harían otros maestros rejeros (Hugo de Ras o de Arrás, alias Ursón y maestro Bartolomé); no obstante, le recompensarán con un total de 18 ducados por dejar lo que había presentado, la traza y las condiciones para ejecutarla. ${ }^{37}$

En cuanto a la presencia y trabajo de Maestro Hilario en Zaragoza, el único que lo había citado entre los artistas que participaron en la dotación artística de la capilla cesaraugustana fue José Ángel Sesma Muñoz en su tesis doctoral sobre la Diputación del Reino de Aragón defendida en 1977. ${ }^{38}$ Ahora se aportan los documentos que lo certifican y que ofrecen detalles sobre su obra zaragozana, que hasta que otros documentos hablen se trataría de la primera reja que forjó el maestro francés en los reinos peninsulares.

La primera noticia sobre la reja está fechada el 4 de noviembre de 1500, cuando los diputados autorizan a don Miguel Torrero, arrendador y administrador de las Generalidades del Reino, a recuperar el dinero que había avanzado, 36 libras, 7 sueldos y 8 dineros jaqueses, para la compra en Valencia de "quatro marquos de plata en foja para platear el rexado de la capilla de la Diputación". ${ }^{39}$

Pocos meses después se comprueba que la Diputación seguía haciendo acopio del material necesario para trabajar la reja de la capilla, pues el 25 de mayo de 1501 se especifica que don Miguel Torrero había "fecho traher de Valencia diez marquos de plata en foja que faltava para platear el rexado de la capilla". El precio de la materia prima ascendía a un total de 1.902 sueldos y seis dineros jaqueses, junto a los derechos de salida del Reino de Valencia y los derechos de entrada al Reino de Aragón. ${ }^{40}$

Esta plata comprada en Valencia en 1500-1501 es la que utilizarían los maestros rejeros Bernaldino Rodríguez y Juan de Casanova, que en una entrada de las cuentas del General de 1502-1503 constan cobrando por platear y labrar barras para la reja de la capilla: "maestre Bernaldino Rodríguez et a maestre Johan de Casanova por plantear y labrar las baras del rexado de la capilla". ${ }^{41}$ Por el desarrollo posterior de la reja de la capilla que se expondrá a continuación no sabemos si el trabajo realizado por los dos rejeros iba destinado a otra lugar de la capilla o lo que se hizo no satisfizo a los Diputados, que lo desecharon y por ello fueron a buscar a Maestro Hilario.

La primera mención documental sobre el maestro rejero francés aparece el 9 de mayo de 1503 [fig. 9]. Ese día, los Diputados del Reino de Aragón ordenaban a don Juan Torrero y don Pedro Sánchez que pagasen a "mastre Ylarya, maestro de fazer raxados" por el material necesario para la ejecución de una reja destinada a "magnificar la capilla de la Diputación en el portalado que está ante de entrar en la dicha capilla". ${ }^{42}$ En la cautela se dice que Maestro Hilario había venido a

\footnotetext{
${ }^{36}$ Gallego, 1983: 220-222; 1987: 14-19 y 1990: 322-327; Speranza, 2001: 23, concr. nota 9.

37 El dibujo de la traza presentado por Hilario se conserva en el Museo de la Catedral de Coria. García, 2004: $137-$ 172.

${ }^{38}$ Sesma, 1977: 164.

${ }^{39}$ Zaragoza, ADPZ, Registro de los Actos Comunes de la Diputación del Reino, 1500-1501, ms. 90, f. 28r (f. 23r antiguo).

${ }^{40}$ Zaragoza, ADPZ, Registro de los Actos Comunes de la Diputación del Reino, 1500-1501, ms. 90, f. 57r (f. 51r antiguo).

${ }^{41}$ Zaragoza, ADPZ, Cuentas del General de Reino, 1502-1503, ms. 89, f. 174r.

${ }^{42}$ Zaragoza, ADPZ, Registro de los Actos Comunes de la Diputación del Reino, 1502-1503, ms. 92, f. 55v (f. 51v antiguo).
} 



Fig. 9. Folio $55 v$ (detalle) del Ms. 92 con la primera cita a Maestro Hilario. Fuente: ADPZ.

Aragón para realizar la reja de hierro estañado con sus fajas doradas, cuyo material pesaba un total de 43 arrobas y cuyo precio final ascendía a 1.240 sueldos, de los que ya se le habían avanzado 400 sueldos y en ese momento cobraba los restantes 840 sueldos que le quedaban por cobrar.

El mes siguiente, concretamente el 30 de junio de 1503, Maestro Hilario ya había puesto manos a la obra y "tenía conpeçado el dicho raxado", pagándosele 2.000 sueldos "para mercar fierro y para proseguir la dicha raxa". Esta carta de pago informa del precio total capitulado por la pieza, 8.000 sueldos. ${ }^{43}$

Hay consignados dos pagos en los que Maestro Hilario necesitó de avaladores para que los diputados le adelantasen ciertas cantidades. En un primer adelanto de 100 libras el 28 de junio de 1503, salieron como fiadores el pellejero maestre Robert y los maestres Juan de Espot y Martín de Icanal. ${ }^{44}$ Meses más tarde, el 25 de agosto de aquel mismo año, era el platero Gabriel de San Malo, ${ }^{45}$ habitante de la ciudad de Zaragoza en aquel momento, el que le avalaba por un adelanto de otras 100 libras ante los señores diputados. ${ }^{46}$

El 17 de octubre de 1503 cobraba 1.200 sueldos más. Hasta ese momento ya había cobrado 6.000 sueldos. ${ }^{47}$ Meses más tarde, el 21 de diciembre de ese mismo año se le volvía a pagar por su trabajo. En ese momento, "porque con mucha diligencia e solicitut obre y acabe la dicha rexa" se le pagaban 500 sueldos, que hasta la fecha suponía haber cobrado en diversas tandas un total de 6.500 sueldos hasta ese día. ${ }^{48} \mathrm{Y}$ el 8 de marzo de 1504 se le pagan 500 sueldos más "porque con mucha diligencia e solicitut obre y acabe la dicha rexa". ${ }^{49}$

\footnotetext{
${ }^{43}$ Zaragoza, ADPZ, Registro de los Actos Comunes de la Diputación del Reino, 1503-1504, ms. 94, f. 17r (f. 12r antiguo).

${ }^{44}$ Zaragoza, ADPZ, Registro de los Actos Comunes de la Diputación del Reino, 1503-1504, ms. 94, f. 123r (f. 144r

${ }^{45}$ Por aquellos años hubo un argentero activo en Zaragoza de nombre Gabriel de Somalo.

${ }^{46}$ Zaragoza, ADPZ, Registro de los Actos Comunes de la Diputación del Reino, 1503-1504, ms. 94, f. 122v (f. 143v antiguo).

${ }^{47}$ Zaragoza, ADPZ, Registro de los Actos Comunes de la Diputación del Reino, 1503-1504, ms. 94, f. 53r (f. 48r

${ }^{48}$ Zaragoza, ADPZ, Registro de los Actos Comunes de la Diputación del Reino, 1503-1504, ms. 94, f. 65v (f. 60v antiguo).

49 Zaragoza, ADPZ, Registro de los Actos Comunes de la Diputación del Reino, 1503-1504, ms. 94, f. 85r/v (f. 80r/v antiguo).
} antiguo). antiguo). 
La reja estaba ya concluida y asentada en la capilla el 26 de abril de 1504, cuando los diputados ordenan a don Felipe Dortal, arrendador y administrador de las Generalidades del Reino, que le pague a Maestro Hilario 1.000 sueldos que le quedaban por cobrar del total de 8.000 sueldos pactados, más otros 30 florines de oro por detalles no previstos en la capitulación que el rejero se había ofrecido a realizar y que magnificaban la reja. ${ }^{50}$

Aunque no contamos con el contrato que sin duda aportaría detalles sobre la estructura y decoración de la reja hecha por Maestro Hilario en Zaragoza, por los documentos antes citados se sabe o se puede inferir alguna de sus características. Sabemos con certeza que los barrotes de hierro se estañaron, es decir, que llevaban un acabado final por el que se recubrieron de estaño para protegerlos de la corrosión. Por otra parte, su demostrada pericia en los labrados de chapa recortada de la barandilla de la Escalera Dorada de la catedral de Burgos [figs. 10 y 11] da pleno sentido a las demasías que se le pagaron por detalles no contemplados en principio, que bien podría tratarse de alguna decoración de las "fajas" (frisos) o la crestería (de tenerla).

En total, maestro Hilario cobraría por su reja 8.600 sueldos (los 8.000 pactados por contrato más 30 florines de demasías - que equivalían a 600 sueldos-).

Como ya pasara con el retablo de alabastro, la reja sería igualmente policromada y dorada por Antón de Aniano, que entre el 6 de abril de 1503 y el 26 de abril de 1504 cobraba de los diputados ciertas cantidades por ese trabajo. ${ }^{51}$

\section{Historia patrimonial de la capilla}

Como es natural en edificios de uso prolongado en el tiempo, las casas de la Diputación precisaron de actividades periódicas de mantenimiento, puntuales reformas o nuevas incorporaciones a su patrimonio mueble. Ya a principios de la década de los años noventa del siglo XV se tuvieron que realizar unas obras urgentes de reparación del muro del edificio que miraba al río Ebro, concretamente de los alicaces que permitían el drenaje del agua; unas obras realizadas entre 1491 y 1492 en las que estuvo involucrado el propio Morlanes junto al maestro de obras Domingo de Urruzola.$^{52}$ Reformas que serían especialmente intensas durante la segunda mitad del Quinientos, cuando también se enriqueció artísticamente de forma notable..$^{53}$

Durante una de ellas, focalizada en la capilla e iniciada en 1621 por impulso de don Francisco de Gurrea y Aragón, duque de Villahermosa y diputado del Reino, el retablo se vería afectado de forma directa. Los días 7, 13 y 31 de marzo, el duque firmaba contratos con los obreros de villa Juan de Santos y Martín Miguel y con el "escultor del Reyno" Juan Miguel Orliens. Los primeros tenían que trasladar, asentar y limpiar pieza a pieza el retablo para realizar una bóveda de ladrillo en el lugar que ocupaba y construir una nueva sacristía tras él en su nueva ubicación; un complicado y peligroso movimiento del retablo que implicaba una cláusula preventiva: "si se quebrase alguna figura o alguna de las pieças de dicho retablo la a de hacer tal y tan buena a su costa" ${ }^{54}$ Mientras, el escultor oscense se comprometía contractualmente a "limpiar el retablo y rexado y assentar las piedras de alabastro y dalle talle a los ángeles y reparalles las caras que se han de añadir en dicho altar". ${ }^{55}$ Como vemos, Orliens también se tenía que ocupar de la limpieza

50 Zaragoza, ADPZ, Registro de los Actos Comunes de la Diputación del Reino, 1504-1505, ms. 94, f. 94v (f. 89v antiguo). Documento inédito publicado en el Apéndice documental, Documento 2.

51 Morte, 1987a: 136-138.

52 Zaragoza, ADPZ, Registro de los Actos Comunes de la Diputación del Reino, 1491, ms. 76, f. 25v (antiguo 19v); 1492, ms. 77, f. 16v-17r (antiguo 13v-14r) y f. 18r (antiguo 14r). Referencias inéditas a excepción de la última, dada a conocer por Álvarez; Casabona, 1989: 72.

53 Domínguez, 2017.

54 Zaragoza, ADPZ, Registro de los Actos Comunes de la Diputación del Reino, 1620-1621, ms. 356, ff. 357-359v (folios a continuación del f. 134 antiguo). Documento dado a conocer y publicado por Redondo, 1981: $203-206$.

55 Zaragoza, ADPZ, Registro de los Actos Comunes de la Diputación del Reino, 1620-1621, ms. 356, f. 356r y f. 136v (folios a continuación del f. 134 antiguo). Documento dado a conocer y publicado por Redondo, 1981: $206-207$. 

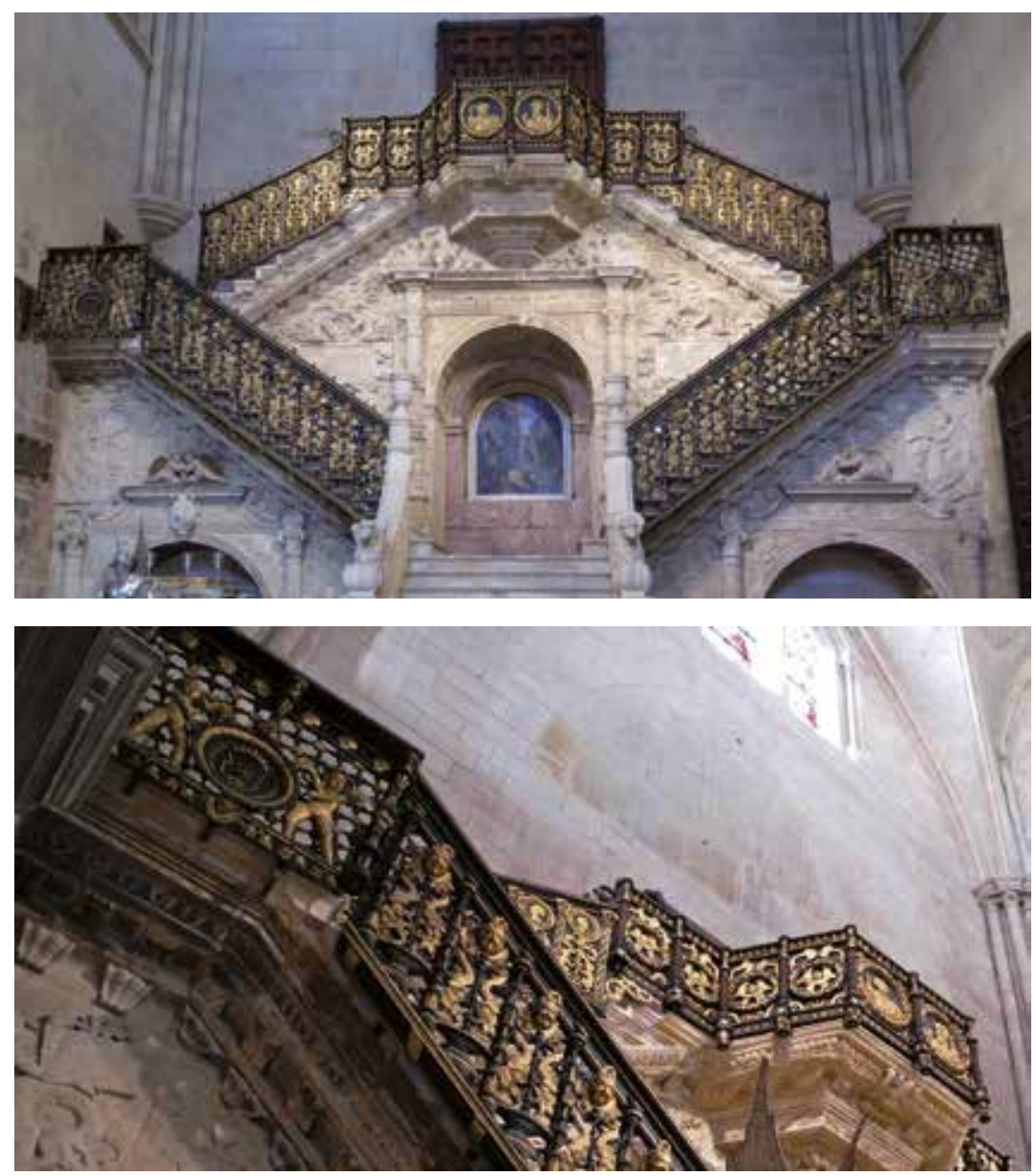

Figs. 10 y 11 . Vista completa y detalle del barandal de la Escalera Dorada de la catedral de Burgos. Fuente: Santos M. Mateos y José Antonio Gárate.

de la reja forjada más de un siglo antes por maestro Hilario y también hacer sobre ella "de madera y maçoneria un frontispicio y cornijamento que corra de largo a largo, encarcelado en las dos paredes, firme y seguro".

Un siglo después, el palacio sería transformado en sede de la Real Audiencia de Zaragoza tras los decretos de Nueva Planta del Reino de Aragón impuestos por Felipe v entre 1707-1711. En ese contexto, y en una relación de objetos de valor realizada en 1708, Alhajas que tenía el Consistorio de la Diputación del Reino de Aragón, al tiempo de su extinción en el año de 1707 y el destino que se les dio en el siguiente de 1708, se habla del cortinaje confeccionado por Antón de Aniano y se explica su función: "Dos cortinadas de olandilla morada para cubrir el Altar en Semana Santa". ${ }^{56}$

Unos años después, el consejero real y oidor del rey en la institución, don Ignacio de Fuertes y Sierra realizará un inventario entre los días 16 y 19 de junio de 1734, el Inventario de las alhajas de la Casa de la Real Audiencia del Reino de Aragón y de la Capilla de la cárcel de Corte. ${ }^{57} \mathrm{Al}$ relacionar los objetos que se encontraban en la capilla, hace esta descripción del retablo, las cortinas de holandilla y la reja:

${ }^{56}$ Zaragoza, ADPZ, Ms. 755-5ㅇ, f. 7v y otra vez en f. 9v.

${ }^{57}$ Archivo Histórico de Protocolos Notariales de Zaragoza (AHPZ), Audiencia, Real Acuerdo. Partido de Zaragoza, expedientes caja años 1734-1737. Publicado íntegramente por Ximénez de Embún González, 1995: 226-244. 
Capilla del Acuerdo

Item un retablo de alabastro de talla con los Misterios de la Pasión de Nuestro Señor Jesuchristo y Nuestra Señora con el Niño sentada en una silla.-

Item para tapar dicho retablo dos cortinas de olandilla azul muy viejas con su barra de hierro.-

$[\ldots]$

Item en el enrregado de dicha capilla dos barras de yerro que cojen todo el enrrejado y en la esquina de el una campana pequeña. $-^{58}$

Es decir, el retablo, el cortinaje y la reja aún estaban allí. En cuanto al retablo, la descripción, aunque somera permite conocer un poco más sobre su iconografía: los relieves tallados por Morlanes incluían también historias de la Pasión de Cristo, que acompañarían a una estructura central dedicada a la Virgen y unos laterales ocupados por historias de San Jorge y Santa Engracia. Por otra parte, el inventario confirma un detalle más que interesante: la estructura de cortinajes que permitía taparlo no sería algo temporal mientras la máquina no disponía de las puertas pintadas por Pedro de Aponte. Al contrario, mientras las puertas parece que se desmontaron, ${ }^{59}$ las dos cortinas y la barra de hierro que se encargaron a Antón de Aniano en 1503 estaban todavía instaladas en 1734.

Allí permanecerían retablo y reja tardogóticos hasta principios del siglo XIX, cuando el palacio sufriría graves daños durante el bombardeo del 27 de enero de 1809 y el posterior incendio durante el segundo sitio del ejército francés. Aunque tradicionalmente se había atribuido a los Sitios de la Guerra de la Independencia la ruina de uno de los más relevantes edificios bajomedievales de Zaragoza ${ }^{60}$ es probable que las principales pérdidas se produjesen inmediatamente después ${ }^{61}$ cuando el edificio sería literalmente abandonado a su suerte por las autoridades y finalmente sustituido a partir de 1830 por una nueva construcción, el Seminario Conciliar.

Sea como fuere, está claro que ambas piezas artísticas se destruirían o trasladarían a otro lugar entre 1809 y 1830 . En el terreno de la pura especulación y dando crédito al comentario escrito por el artista y erudito Valentín Carderera y Solano en 1835, según el cual se habían conservado algunos fragmentos del retablo de San Jorge que presidía la Real Sala de San Jorge o Sala Real que "se han destruido para hacer cal", ${ }^{62}$ quién sabe si algo parecido pasaría con el retablo de Morlanes y la reja de Hilario.

Por otro comentario publicado igualmente en El Artista un año más tarde, que denunciaba la destrucción del rico patrimonio arquitectónico de Zaragoza, parece probable que así fuera en el caso del retablo, pues el autor comenta que "Muchos trozos aunque mutilados de excelente escultura y adornos de los Anchetas y Forments, que hacían parte del célebre edificio de la casa de la diputación, nos han asegurado que se han convertido en cal para ahorrar algunos reales de este material!!" ${ }^{33}$ Como ya venía siendo habitual en la historiografía desde el siglo XVII, era común que el retablo de San Jorge fuera atribuido a Anchieta, ${ }^{64}$ como también lo era que las obras de Morlanes le fueran atribuidas a Damián Forment, por lo que esos fragmentos bien pudieran ser del retablo que aquí se trata.

\footnotetext{
${ }^{58}$ AHPZ, Audiencia, Real Acuerdo. Partido de Zaragoza, expedientes caja años 1734-1737, ff. 6v. y 7v. Ximénez de Embún González, 1995: 234-235.

${ }_{59}$ De estar instaladas no cabe la menor duda que se hubieran incorporado al inventario. En cambio, una de las entradas bien pudierán ser estas puertas: "Item un biombo rollado de seis lienzos pintado por una y otra cara de tres varas de alto." AHPZ, Audiencia, Real Acuerdo. Partido de Zaragoza, expedientes caja años 1734-1737, f. 7r. Ximénez de Embún González, 1995: 235.

${ }^{60}$ Salord, 1956.

${ }^{61}$ Como bien relata Bitrián, 2014.

${ }^{62}$ Carderera, 1835: 169.

${ }_{63}$ T. O., 1836: 21.

${ }^{64}$ Gracias a Carmen Morte García se sabe que fue una obra contratada en 1598 por el escultor navarro Pedro González de San Pedro, discípulo de Juan de Anchieta, en Morte, 1987b: 61-112.
} 


\section{Cierre}

Maravillados por la exuberancia decorativa de la Sala Real del primer piso del palacio, los cronistas y viajeros que pasaron por Zaragoza no le dispensaron mucha atención a la capilla. Un buen ejemplo de ello es uno de los oficiales franceses que participó en el asedio de la capital aragonesa el año 1809, el barón de Férussac, que cuando recoge en su diario los principales edificios de la ciudad y habla del palacio de la Diputación sólo tiene ojos para aquel espacio, no comentando absolutamente nada de la capilla. ${ }^{65}$

No obstante, y a tenor de los artistas que trabajaron en ella, como el rejero francés Hilario, considerado como uno de los "grandes maestros de la forja del hierro en el primer cuarto del siglo, época que veníamos calificando como la más sugestiva e interesante dentro de la historia del arte del hierro en España", ${ }^{66}$ o el escultor darocense Gil Morlanes, escultor real de Fernando II «el Católico», de conservarse sin duda se trataría de una obra culmen de los reinos peninsulares en un momento artístico bisagra, cuando los últimos estertores del gótico dejaban paso a los primeros silabeos del Renacimiento.

\section{BIBLIOGRAFÍA}

Abizanda y Broto, Manuel (1915): Documentos para la historia artística y literaria de Aragón procedentes del Archivo de Protocolos de Zaragoza. Siglo XVI, t. I. Zaragoza: Tip. La Editorial, pp. 25-26.

Álvarez Gracia, Andrés / Casabona Sebastián, José F. (1989): "La Casa de la Diputación del Reino”. En: La plaza de la Seo. Zaragoza: investigaciones Histórico-Arqueológicas, Sección Municipal de Arqueología. Zaragoza: Excmo. Ayuntamiento de Zaragoza, pp. 61-75.

Bitrián Varea, Carlos (2014): Lo que no (solo) destruyeron los franceses. El ocaso del palacio de la Diputación del Reino de Aragón. Zaragoza: Institución «Fernando el Católico», Excma. Diputación de Zaragoza.

Carderera y Solano, Valentín (1835): "Bellas Artes. vII". En: El Artista, I, Madrid, 5 de enero, pp. 169-172.

D’Audebard, André-Étienne-Just-Paschal-Joseph-François, barón de Férussac (1816): Journal historique du siége de Saragosse, suivi d'un Coup d'œil sur l'Andalousie. París: Librairie d'éducation et de jurisprudence d'Alexis Eymery.

Domínguez Montero, Diego (2017): "Pervivencias y renovaciones en las Casas de la Diputación del Reino de Aragón. Obras de reforma, mantenimiento y decoración durante la segunda mitad del Quinientos. Una revisión necesaria". En: Ibáñez Fernández, Javier (coord. y ed.): Del mecenazgo a las nuevas formas de promoción artística. Actas del XIV Coloquio de Arte Aragonés. Zaragoza: Prensas de la Universidad de Zaragoza, pp. 281-296.

Gallego de Miguel, Amelia (1983): "El arte del hierro en la Catedral de Burgos". En: Boletín de la Real Academia de Bellas Artes de San Fernando, 57, Madrid, pp. 211-240.

Gallego de Miguel, Amelia (1987): "El maestro Hilario". En: Goya. Revista de arte, 199-200, Madrid, pp. 14-19.

Gallego de Miguel, Amelia (1990): "El sepulcro del arzobispo Anaya Maldonado, de la Catedral Vieja de Salamanca, y la obra del maestro Hilario". En: Goya. Revista de arte, 216, Madrid, pp. 322-327.

García Mogollón, Florencio-Javier (2004): "Precisiones documentales sobre la reja de la capilla mayor de la catedral de Coria. Las intervenciones de Hilario Francés, Ursón y Bartolomé de Jaén”. En: Laboratorio de Arte. Revista del Departamento de Historia del Arte, 17, Sevilla, pp. 137-172.

Giménez Arbués, Chesús Á. / Tomás Faci, Guillén (2006): "Imágenes inéditas de la sede de la Diputación del Reino". En: Aragón turístico y monumental, 360, Zaragoza, pp. 15-19.

Gómez Urdáñez, Carmen (2011): "La sede de la Diputación de Aragón en las casas del Reino". En: Reyes de Aragón: soberanos de un País con futuro. Ramiro I-Juan Carlos I (1035-2011). Zaragoza: Diputación General de Aragón e Ibercaja, pp. 358-369.

Ibáñez Fernández, Javier (2000): "Precisiones sobre la política artística de don Alonso de Aragón, arzobispo de Zaragoza (1478-1520)”. En: Boletín del Museo e Instituto de Humanidades “Camón Aznar”, LXXXII, Zaragoza, pp. 293-305.

Janke, R. Steven (1988): “Gil Morlanes the Elder: gothic works restudied”, The Fifteenth Century. En: Acta, The Center for Medieval and Early Renaissance Studies, State University of New York at Binghamton, XII, Nueva York pp. 61-80.

${ }^{65}$ D’Audebard, 1816: 92. Algo que no debe sorprender, ya que al describir el Templo del Pilar o la catedral de San Salvador no dedica ni una sola palabra a sus imponentes retablos mayores de Pere Joan, Hans Piet Danso y Damián Forment.

${ }^{66}$ Gallego, 1990: 324-325. 
Mateos Rusillo, Santos M. (2001): "La figura del artista-empresario en la escultura de la Corona de Aragón: Gil Morlanes el Viejo". En: Actas del Congreso Internacional sobre Gil Siloe y la Escultura de su época, Institución Fernán González y Academia Burgense de Historia y Bellas Artes, Burgos, pp. 551-557.

Morte García, Carmen (1981): "Miguel Ximénez y Gil Morlanes el Viejo, artistas de Fernando el Católico". En: Miscelánea en honor de Antonio Durán Gudiol, Sabiñánigo, pp. 215-223.

Morte García, Carmen (1987a): "Documentos sobre pintores y pintura del siglo Xvi en Aragón. I”. En: Boletín del Museo e Instituto de Humanidades "Camón Aznar”, XXX, Zaragoza, pp. 117-231.

Morte García, Carmen (1987b): "Dos ejemplos de las relaciones artísticas entre Aragón y Navarra durante el Renacimiento. El Retablo del Tránsito de María, en Tulebras (Navarra) y el Retablo de San Jorge de la Diputación de Aragón, en Zaragoza”. En: Revista Príncipe de Viana, 180, Pamplona, pp. 61-112.

Morte García, Carmen (1998): "Los arzobispos de la Casa Real: don Alonso, don Juan y don Hernando de Aragón (14781575)”. En: La Seo de Zaragoza, Zaragoza: Diputación de Aragón, pp. 175-247.

Redondo Veintemillas, Guillermo (1981): "Una reforma de la capilla de la Diputación del Reino de Aragón en 1621: contratos para su realización”. En: Seminario de Arte Aragonés, xxxIII, Zaragoza: Institución «Fernando el Católico», Excma. Diputación de Zaragoza, pp. 201-207.

Salord Comella, Santiago (1956): "La casa de la Diputación de la generalidad de Aragón: notas históricas”. En: Estudios de Edad Media de la Corona de Aragón, VI, Zaragoza: Escuela de Estudios Medievales, pp. 247-265.

Schaschek, Vaclav (1879): "Viaje del noble boemio Leon de Rosmital de Blatna, por España y Portugal, hecho del año 1465 a 1467”. En: Fabié, Antonio María: Viajes por España de Jorge de Einghen, del Barón Leon de Rosmithal de Blatna, de Francisco Guicciardini y de Andrés Navajero. Madrid: Imprenta de Aribau y Compañía (sucesores de Rivadeneyra), pp. 47-154.

Serrano y Sanz, Manuel (1916): "Gil Morlanes, escultor del siglo XV y principios del XVI". En: Revista de Archivos, Bibliotecas y Museos, XXXIV, Madrid, pp. 351-380.

Serrano y Sanz, Manuel (1918a): "Gil Morlanes, escultor del siglo XV y principios del XVI". En: Revista de Archivos, Bibliotecas y Museos, XXXVI, Madrid, pp. 92-102.

Serrano y Sanz, Manuel (1918b): "Gil Morlanes, escultor del siglo XV y principios del XVI". En: Revista de Archivos, Bibliotecas y Museos, XXXVII, Madrid, pp. 357-359.

Sesma Muñoz, José Ángel (1977): La Diputación del Reino de Aragón en la época de Fernando II (1479-1516). Zaragoza: Institución «Fernando el Católico», Excma. Diputación de Zaragoza.

Speranza, Fabio (2001): "La escalera dorada de la catedral de Burgos”. En: Archivo Español de Arte, 293, pp. 19-44.

T. O. (1836): "Comunicado". En: El Artista, III, Madrid, 1 de julio, pp. 20-22.

Velasco Gonzàlez, Alberto (2020): “De nuevo sobre Pedro de Aponte, pintor del Primer Renacimiento en Aragón”. En: Ars \& Renovatio, 8, pp. 4-41.

Ximénez de Embún González, Ana (1995): "Inventario de las alhajas de la Casa de la Real Audiencia del Reino de Aragón y de la Capilla de la cárcel de Corte (1734)”. En: Emblemata. Revista aragonesa de emblemática, 1, Zaragoza, pp. 226-244.

Ximénez de Embún y Val, Tomás (1901): Descripción Histórica de la antigua Zaragoza y de sus términos municipales. Zaragoza: Librería de Cecilio Gasca.

Yarza Luaces, Joaquín (1993): Los Reyes Católicos. Paisaje artístico de una monarquía. Madrid: Nerea.

Yarza Luaces, Joaquín (1994): "Posible respuesta a una duda: el maestro desconocido del retablo gótico de Ejea de los Caballeros y el artista empresario". En: Tiempo y Espacio en el Arte. Homenaje al profesor Antonio Bonet Correa, I, Madrid, pp. 149-160.

Apéndice documental ${ }^{67}$

\section{Documento 1}

1502 julio 18. Zaragoza

Carta de fin de pago de 200 ducados a Gil Morlanes por la obra del retablo de alabastro de la capilla de la Diputación del General, capitulado por 1.200 ducados.

R. Zaragoza, ADPZ, Registro de los Actos Comunes de la Diputación del Reino, 1502-1503, ms. 92, ff. 22v-23r (ff. 18v-19r antiguo).

${ }^{67}$ De toda la documentación inédita exhumada, por cuestiones editoriales se han seleccionado para su publicación solo dos documentos, los que aportan más información sobre el retablo (Documento 1) y la reja (Documento 2). 
Los $^{1}$ dipputados del Regno de Aragón. A los honorables Johan Torrero et Pedro de Johan Sánchez, administradores de las generalidades del Regno de Aragón, salut et aparellada voluntat a vuestra honor. Por quanto por los dipputados, predeçessores nuestros, fue dado cargo a maestre Gil de Molrrans, pedrapiquero, fiziesse hun retablo delabastro con las istorias de la coronación de Nuestra Sennora y sant Jorge e santa Engracia a los costados, para la capilla que se ha fecho dentro de la Dipputación. El qual retablo fue avenido con el dicho maestre Gil, aquel atemado, asentado y puesto en perfección como havía de estar, en mil y dozientos ducados de oro, segunt está et pareçe por cierta capitulación fecha et concordada por los dichos dipputados et el dicho maestre Gil. Y por razón de la dicha obra tenga ya reçebidos en parti- $\left.\right|^{f .23 r}$ das y por cautelas de los dichos dipputados mil ducados, açerqua lo qual le quedarían por pagar, a complimiento de los dichos mil y dozientos ducados del dicho retablo, dozientos ducados. E sea justa cosa, pues el dicho maestre Gil ha dado todo complimiento en la dicha obra, puesta y asentada como havía de estar y segunt lo capitulado, sea satisfecho y pagado de los dichos dozientos ducados que le quedan por pagar a complimientos ${ }^{2}$ de los dichos mil dozientos ducados. Por tanto, a vosotros, dichos administradores de la part de susso nombrados, dezimos y mandamos que de qualesquiere peccunias del dicho Regno que son o serán en vuestro poder deys et paguéys al dicho maestre Gil, a complimiento de lo que ha de cobrar, los dichos dozientos ducados, car vosotros, dando et pagando aquellos et mostrando la presente con ápocha sufficiente de pago, aquellos en la reddición et examinación de vuestros contos vos serán admesos et tomados en conto sines dubitación et defficultat alguna.

Dada en Caragoca ${ }^{3}$ a XVIII de julio, anyo mil $\mathrm{D}^{\text {os }}$ y dos.

Don Alonso dAragón, dipputado y procurador de mossén Ffrancisco Contamina, Condipputado, don Alonso de Aragón y de Gurrea, dipputado, Ximeno de Hulleta, dipputado, Pedro de Bal, dipputado y procurador de Johan Rodrigo, condipputado.

1. Al margen izquierdo del asentamiento, la nota Cautela de maestre Gil de Molrrans de CC ducados indica el tipo de documento emitido por los diputados. - 2. En lugar de complimiento. - 3. Faltan las dos cedillas.

\section{Documento 2}

\section{4 abril 26. Zaragoza}

Carta de fin de pago de 1.600 sueldos a Maestro Hilario por la obra de la reja de hierro estañado de la capilla de la Diputación del General, capitulada por 8.000 sueldos. En la carta se incluye el pago de unas demasías de 100 florines de oro por detalles no contemplados en principio.

R. Zaragoza, ADPZ, Registro de los Actos Comunes de la Diputación del Reino, 1504-1505, ms. 94, f. 94v (f. 89v antiguo).

$\operatorname{Los}^{1}$ diputados del Reyno de Aragón. Al honorable Felipe Dortal, arrendador e administrador de las generalidades del Reyno de Aragón, salut et cetera. Por quanto mastre Ylario, maestro de fazer rexados, ha fecho la raxa ${ }^{2}$ de la capilla de la Diputación, la qual fue por nosotros avenida en $\mathrm{VIII}^{\mathrm{M}}$ sólidos jaqueses, de los quales tiene recebidos $\mathrm{VII}^{\mathrm{M}}$ sólidos jaqueses y resta que ha de cobrar mil sólidos a complimiento de los dichos VIII ${ }^{\mathrm{M}}$ sólidos. E pues ha dado complimiento a la dicha raxa $^{3}$ e asentado aquella en la dicha capilla, queremos le sian dados e pagados los dichos $\mathrm{I}^{\mathrm{M}}$ sólidos a él restantes por cobrar. E assí mesmo, por algunas cosas que se han offrecido ${ }^{4}$ fazer para magnificar la dicha raxa ${ }^{5}$, las quales no estavan en la capitulación, le havemos tachado cient florines de oro, que es por todo $\mathrm{II}^{\mathrm{M}} \mathrm{DC}^{6}$ sólidos jaqueses. E sea justa e razonable cosa, pues ha dado complimiento en todo con mucha diligencia, sea de sus trebajos satisfecho y pagado. Por tanto, a vos, dicho Felipe Dortal, arrendador e administrador sobredicho, dezimos et cetera deys y paguéys al dicho mastre Ylario los dichos II ${ }^{\mathrm{M}} \mathrm{DC}$ sólidos jaqueses, car vos, et cetera.

Dada en Caragoca ${ }^{7}$ a XXVI días de abril, anno mil $\mathrm{D}^{\text {os }}$ y quatro. 
1. Al margen izquierdo del asentamiento, la nota Cautela de mastre Ylario indica el tipo de documento emitido por los Diputados. - 2. En lugar de rexa. - 3. Ídem. - 4. Sigue pagar tachado. - 5. En lugar de rexa. - 6. El equivalente de cien florines de oro son seiscientos sueldos. El escribano se equivoca al hacer la conversión que suma a los 1.000 que se le adeudaban de la cantidad inicial. En consecuencia, la cantidad a pagar es mil seiscientos sueldos. - 7. Faltan las dos cedillas.

Fecha de recepción:12-XI-2020

Fecha de aceptación: 03-II-2021 